\title{
Research and Practice on the Construction of Digital Manufacturing Maker Laboratory
}

\author{
Weijian Mo \\ Xin Hua College of Sun Yat-Sen University \\ Dongguan, China 523133 \\ Guocheng Li \\ Xin Hua College of Sun Yat-Sen University \\ Dongguan, China 523133
}

\author{
Weilin Li \\ Xin Hua College of Sun Yat-Sen University \\ Dongguan, China 523133 \\ Jia Li \\ Xin Hua College of Sun Yat-Sen University \\ Dongguan, China 523133
}

\begin{abstract}
This paper mainly explains how to explore and propose a maker education model suitable for colleges and universities, how to set up a team of maker teachers, develop teaching resources and establish the first university maker laboratory in Guangdong, and how to offer interdisciplinary creative design courses and identify the feasibility of the overall program by using digital manufacturing education under the national policy and maker education.
\end{abstract}

Keywords—digital; maker space; education

\section{INTRODUCTION}

In response to Premier Li Keqiang's call for "Mass Entrepreneurship and Innovation" and promoting the development and reform of traditional education in schools, the digital manufacturing education and teaching was explored and researched in early 2014, and the Fab Lab Innovation Center was established in December 2014. In order to further promote the digital manufacturing teaching reform, the Center established a joint laboratory with the Massachusetts Institute of Technology (MIT) Fab Lab in February 2015 to share teaching resources and the joint lab became the first university Maker Lab in Guangdong. Approved by the "Fab Academy" in November 2015, it became one of the global teaching sites for digital manufacturing courses. Based on digital manufacturing and interdisciplinary connection, Fab Lab Innovation Center is dedicated to the link of maker resources and the construction of student project platform, etc., and constantly improves and strengthens the software and hardware conditions of the laboratory in practice, aiming at cultivating students' ability of practice and innovation.

\section{Status ANALYSIS OF Digital MANUFACTURING EDUCATION}

In foreign countries, digital personal manufacturing originated from the Fabrication Laboratory (FABLAB) of the Center for Bit and Atomic Research at the Massachusetts Institute of Technology. Currently, for innovation in production and invention, everyone knows that only a very small number of scientists/enterprise hightech personnel and inventors can do, but Neil Gershenfeld talked about the principles of digital devices from the most primitive bits and atoms and analyzed various famous/classical methods and causes, and talked about the future of bits and atoms as well. Besides, he also proposed to collect/purchase various digital devices and tools to build a platform that can produce anything of any size, and establish the first digital assembly laboratory (FABLAB) based on digital manufacturing.

In China, a major breakthrough in digital manufacturing technology is a new manufacturing technology system. The Chinese government has pointed out that the direction of development in the development strategy of manufacturing power and "Made in China 2025" is to cultivate more applied talents. [1] At the executive meeting of State Council in early 2015, Premier Li Keqiang issued to vigorously develop a market-oriented, professional, integrated and networked "maker space" throughout the country, and cultivate all kinds of young creative talents and innovation teams including college students so as to achieve the combination of innovation and entrepreneurship, online and offline, incubation and investment as well as the guidance of "engine" for economic development and innovation. The General Office of the State Council issued the "Guidance on developing the maker space for mass innovation and entrepreneurship" and put forward the eight tasks of promoting "mass entrepreneurship and innovation", laying a policy foundation for the development of maker education in colleges and universities of China.

Digital manufacturing technology is widely used in the manufacturing field, but it is not universal in the teaching field. Tracing back the famous digital manufacturing teaching source, Fab Lab, micro assembly laboratory of the Center for the study of bits and atoms in Massachusetts Institute of Technology, established the Fab Academy for Fab Lab to teach students how to make everything. It's needed that making In-depth investigation, learning Fab Academy digital manufacturing teaching model, and 
building a localized teaching model of maker education based on the characteristics of the school itself.

\section{LABORATORY CONSTRUCTION}

Practice teaching in higher education institutions is one of the main forms of practical education. The Fab Lab Innovation Center is an open maker laboratory. The existed main problems in the traditional open laboratory construction include : first, Insufficient understanding and attention to the positioning of the laboratory; second, marginalization of the laboratory faculty and a lack of longterm planning; third, outdated and traditional laboratory management method; fourth, lacking effective means of laboratory evaluation. [2] Therefore, in order to ensure the operation of experimental teaching, we need to overcome the problem and defects in laboratory construction, avoid various operation mine field of laboratories, define the target orientation of the center, and assist local enterprises to enhance the local economy as well as cultivate innovative application-oriented talents. Besides, we should develop a new teaching model in line with Maker education and teaching, set up a professional team of maker instructors, equip with relatively complete project processing tools such as new laser engraving machines, garment plotters, cutting plotters, CNC milling machines, SRM-20 Roland bench cutting machines, 3D printers, 3D scanners, photocuring 3D printers, drilling machines, sawing machines and so on. Cooperating with Gizwits, Mileage science and technology, South China Maker Network Technology Company and others carry out school-enterprise cooperation to provide conditions for the project development of students and teachers in our college. Focusing on the social practice, carrying out laboratory construction and management combining theory and practice as well as the joint innovation and open innovation

\section{MAKER TEACHING MODE}

Maker teaching is different from traditional education and teaching. The traditional course teaching is led by teachers, one teacher undertaking the teaching of the whole class and students grow up in the teacher's blackboard teaching mode. But at the Fab Lab Innovation Center, the teacher is not the decisive factor, because the entire course's teaching instructor consists of a Maker instructor and multiple Maker assistants. CDIO is conceived, design, implement, and operate. It was originally founded by four universities, including the Massachusetts Institute of Technology and the Royal Swedish Academy, after four years of research and research. An engineering education model that combines curriculum and practice with a life cycle of product development and operation is taken as the carrier and students as the main body [3]. Based on the CDIO concept, a curriculum system integrating innovation and entrepreneurship education with maker education is constructed.

The center is committed to the practical exploration of maker teaching, actively promotes teaching and continuous improvement, and has now formed a brand-new teaching model. It conducts on-campus public elective courses around the laboratory (interdisciplinary creative design challenge course): Guiding students to use the laboratory digital equipment to create what they want to make and achieve personal manufacturing. There are 60 students in the course per semester. The course content is divided into four parts: project management, computer-aided design, digital production equipment and innovative and creative project production. It develops study in an interdisciplinary manner, and the teacher acts as a guide and assistant, teaching the main line of the course as well as teaching students to use different methods and different tools to achieve independent learning. Based on the project and design, the course cultivates students' innovative thinking and comprehensive application ability by learning laboratory equipment operation such as cutting plotter, laser engraving machine, $\mathrm{CNC}$ milling machine and Roland milling machine, and finally completes the project production. After 3 sessions of teaching practice, making and perfecting their own teaching website to provide reference for other students, this optional course is now in session 7 .

\section{OPEN MODE OF LABORATORY}

University laboratories are important places for students to accept comprehensive quality education. At the same time, the laboratory construction level is also an important criterion for measuring the quality of school teaching facilities. Due to the large number of students in the school, if the laboratory is opened arbitrarily, it will inevitably cause a series of problems, even laboratory safety accidents. Therefore, colleges and universities should develop appropriate solutions to such problems and verify the management mode and operation mechanism of the openoriented maker laboratory through long-term practice. At present, the laboratories of many colleges and universities in China are in a semi-open management model. In order to make full use of the resources of the maker laboratory and improve the efficiency of students' learning, project development and practical teaching, Fab Lab Innovation Center breaks the semi-closed state of the laboratory and boldly adopts a completely open laboratory management model. [4] It is open to all students all day long and provides them with space for practice and independent development. Besides, it organizes and guides students to carry out discipline competition, scientific research projects and other activities, trains students' practical ability and scientific and technological innovation ability by interdisciplinary and cross-disciplinary training mode. The center has made great achievements such as winning the second and third prizes in competition/research project of "National University Internet of Things Application Development Innovation Competition" in south China competition area and its "National Innovation and Entrepreneurship Program for College Students" has gotten provincial project approval. In addition, following the principle of "bringing in and going out", we received international guests and domestic and inter-school visitors nearly 100 times, promoted the maker culture atmosphere of our center; carried out a series of distinctive maker cultural 
exchange activities of Going out, organized students to participate in domestic maker activities and visiting other maker labs, and actively participated in various researches, innovation forums and activities to broaden our horizons and gear to international conventions so as to explore students' interests and guide their learning.

\section{CONSTRUCTION OF EXPERIMENT TECHNICIAN TEAM}

The experimental technical team, similar to the team of teachers and management personnel, plays a pivotal role in the process of school construction and personnel training. Therefore, we need to sort out a suitable and localized full life circle management system, covering the position setting standardizing, job responsibilities clearing, reasonable staffing establishing, talent introduction and talent withdrawal. [5] The college employs experts and professors with many years of experience as directors to guide the work, and equip one experimental teaching staff, one experimental technician, and one organizational management personnel responsible for the normal operation, maintenance, repair and daily work of the laboratory equipment. In order to learn from more experience, the lab teachers visited the MIT Fab Lab at the end of May 2016 to learn their Maker teaching methods, contacted many foreign laboratories through the Fab Lab platform, and helped the young teachers successfully complete the studies in management, mechanical engineering, electronic engineering, computers, materials, mechanics and structure of Fab Academy, and obtained diplomas from the Massachusetts Institute of Technology Fab Academy, introducing new models and concepts for laboratory teaching and better guiding students' creative learning.

In addition, the laboratory also cooperates with the Science and Technology Application and Innovation Center ("Kechuang" for short) and technology community on campus to implement teaching reform. "Kechuang" student organization act as an important bond: internally, "Kechuang" Center encourages students to innovate, produce and create, and it makes full use of the resources and advantages of Fab Lab Innovation Center to innovate entrepreneurial activities, and carries out extensive and friendly cooperation activities with various student associations and student organizations based on the actual situation of our institute to promote makers thinking and communication spirit; externally, the students of the "Kechuang" Center have always adhered to the spirit of the Fab Lab Innovation Center to innovate, open and share, widely participated in all kinds of innovation, creativity, and maker activities, and carried out learning and communication activities with makers around the world, which not only improves students' general knowledge level and comprehensive quality, but also increases the popularity of our college in such innovative and maker activities.

At present, the "Kechuang" Center and the Fab Lab Innovation Center have basically formed an efficient learning model with complementary advantages, mutual learning and common progress. Based on the Fab Lab Innovation Center, "Kechuang" continues to radiate to other student organizations and student entrepreneurial teams in the school, striving to form a maker education model with students' independent learning, teacher-directed Q\&A, and entrepreneurship pilots on campus. Teachers and community students form a technical support team for the laboratory to create a strong technological and cultural atmosphere, thus enhancing students' awareness of science and technology and management innovation, and train students to become the application-oriented and innovative talents needed in the new era.

\section{LABORATORY SAFETY AND ENVIRONMENTAL PROTECTION}

Laboratory safety and the environmental protection construction have become an important issue for colleges and enterprises. China's environmental law also stipulates that all units and individuals have the obligation to protect the environment. There are a great number of equipment in laboratories and dangerous equipment and tools occupy part of it. Besides, the maker project practice involves chemicals and the treatment needs to be addressed. [6] Therefore, according to the regulations of the college laboratory system, combined with the particularity of the Fab Lab laboratory, a set of specifications and safety system suitable for the actual laboratory is formulated and should be taken into practice, and a standardized management mechanism is improved and established. Before entering the laboratory, students should receive equipment safety training first, and complete the registration of "laboratory use records", "laboratory tools borrowing", etc. Each device has corresponding operating instructions and danger identification. During the operation of large equipment, the laboratory administrator or assistant should accompany the students to avoid safety accidents. We should carry out the concept of environmental protection and resource conservation, recycle the waste paper and leather boxes on campus for the daily creation of college students, and cultivate the consciousness of putting the laboratory tools, desks and chairs back, so that students can form good habits and keep the laboratory clean and tidy in usual.

\section{INSTRUMENT MAINTENANCE AND PROTECTION}

Large-scale instruments and equipment are important guarantees for teaching and research in universities, as well as important indicators for measuring the experimental conditions and research environment of a university, and the basis for cultivating high-quality and innovative talents. [7] The Fab Lab Innovation Center Maker Lab includes large $\mathrm{CNC}$ equipment and high-risk electric tools.

Therefore, laboratory management personnel should read the equipment instructions carefully and register daily use. If finding any abnormal condition, they can deal with it as soon as possible, and instruct students to strictly abide by the equipment operation rules, use the equipment correctly, reduce equipment wear, and stop working immediately if there is any equipment failure, find out the reason as soon as possible, and carry out maintenance. According to the characteristics and requirements of the equipment, we should develop corresponding maintenance measures, such 
as controlling the temperature of the $3 \mathrm{D}$ printer environment, paying attention to the moisture-proof and dust-proof of the laser engraving machine, and often cleaning and lubricating the CNC milling machine to eliminate equipment failures in time and extend the service time of the equipment, carefully following and regularly maintaining and inspecting the equipment to improve the equipment management system constantly.

\section{CONCLUSION}

Through the exposition of the whole process of conception, construction and operation of Xinhua Maker Laboratory in Xinhua College of Sun Yat-sen University, the writer hopes to give a reference to the education units have not or have established maker laboratories.

\section{REFERENCES}

[1] Tan Xiaoman, Zhou Hua, Zhang Zhong. Discussion on Educational Digital Intelligent Manufacturing System [J]. Mechanical \& Electrical Engineering Technology,2017,46(8):56-58.

[2] Wang Xiaohua, Wang Jie, Li Haiyan, Yang Huiru, Wang Hong. Exploration on the Open Laboratory Construction in Colleges and Universities [J].Research and Exploration in Laboratory, 2013, 23(9): 119-221.

[3] Zhu Xiaodong, Gu Rongrong, Wu Libao. Research on the Integration of Innovation and Entrepreneurship Education and Professional Education Based on CDIO Concept, 2018(2): 77-80.

[4] Gao Weichao, Huang Gang, Yin Chanjuan, Guo Sheng. The Application of Open-oriented Mode in University Laboratory Management [J].Experimental Technology and Management, 2017,34(7):235-238.

[5] Zhang Lei, Hou Dejun, Shao Lan, Zhang Sherong. Construction of the Full Life Circle Management System of Experimental Technology Team [J]. Experimental Technology and Management, 2018, 35(2): 251-255.

[6] Wang Yanqin. Construction of an Independent College Laboratory Safety and Environmental Protection Standard Management System [J]. Experimental Technology and Management, 2017, 34 (12): 275282.

[7] Zhao Yang. Discussion on the Safe Use and Maintenance of Largescale Instruments and Equipment in Colleges and Universities [J]. Gaoxiao Shiyanshi Gongzuo Yanjiu, 2017 (03): 131-135. 